\title{
Preface: International Symposium on Quantum Fluids and Solids (QFS2018)
}

\author{
Hiroshi Fukuyama ${ }^{1} \cdot$ Makoto Tsubota $^{2} \cdot$ Takeo Takagi $^{3} \cdot$ Hyoungsoon Choi $^{4}$ \\ Published online: 6 June 2019 \\ (c) Springer Science+Business Media, LLC, part of Springer Nature 2019
}

The International Symposium on Quantum Fluids and Solids (QFS2018) was held at the Ito International Research Center on Hongo campus of the University of Tokyo, Japan, from July 25 through 31, 2018. QFS is the main conference for the research community of quantum fluids and solids. It is held every year at different international sites except in years when the International Conference on Low Temperature Physics (LT conference) is held. This was the 23rd event of the series. The history of the QFS conference series is described in http://people.umass.edu/ qfs 98/info1.htm. This special issue of the Journal of Low Temperature Physics (JLTP) contains 40 published papers which were submitted as proceedings papers for QFS2018. Each paper was refereed by two independent reviewers under standard criteria for regular papers of JLTP.

QFS2018 attracted 223 registered participants from 20 different countries. Japan had the largest number of participants followed by USA (29), Finland (11), UK (11), China and Taiwan (8), Russia (8), France (7), Korea (6), Canada (4), Czech Republic (4), Germany (4), etc. The number of student participants was 59.

The symposium covered not only its central topics, such as superfluid helium, quantum solids, helium in nanopores, quantum turbulence and cold gases, but also

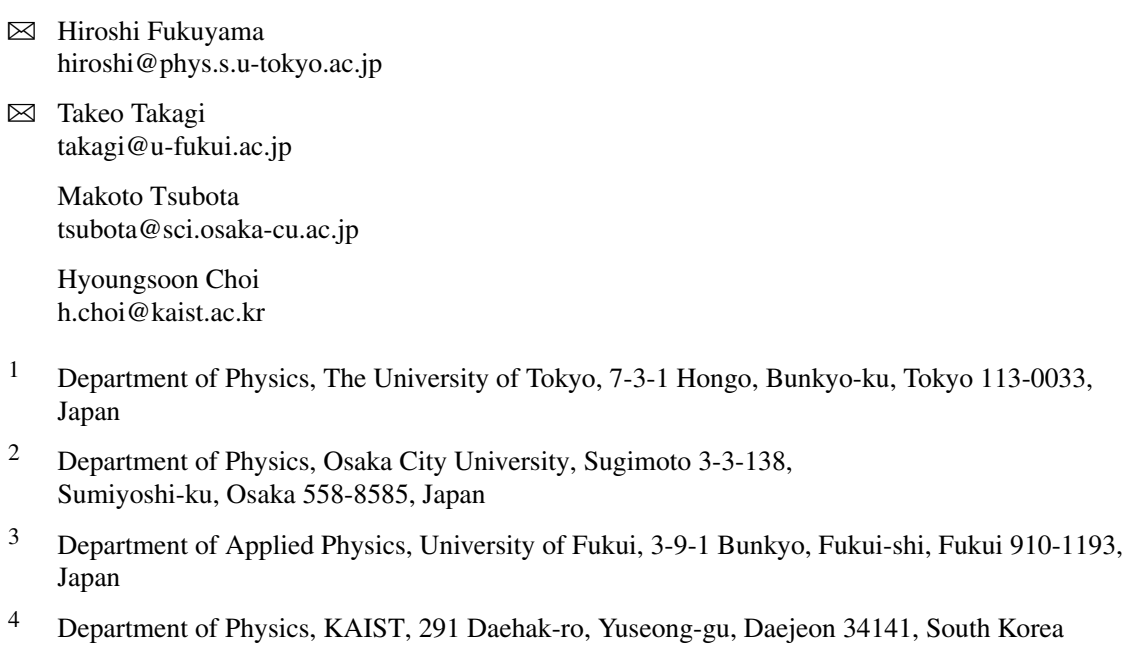


interdisciplinary topics like quantum spin liquids, quantum information, unconventional superconductors, neutron stars and novel low-temperature techniques.

Throughout the symposium, 12 plenary and 41 invited talks were given including those by two Nobel laureates. One is Anthony J. Leggett who gave the opening talk of the symposium. The other is Michael J. Kosterlitz who gave a talk with John Reppy in the memorial session celebrating prize winning theoretical and experimental discoveries of the Kosterlitz-Thouless (or BKT) transition in superfluid helium films. In addition, 147 posters were presented. Each poster was displayed for two successive symposium days for extensive discussions. The Poster Award Committee chaired by Paul Leiderer awarded the Best Poster Awards to 6 young researchers, who gave excellent poster presentations, at the final symposium day.

The scientific program was arranged by the Program Committee chaired by Makoto Tsubota based on suggestions from the International Program Advisory Committee that consists of 28 international scholars. The session devoted for neutron stars was co-arranged with Interdisciplinary Theoretical and Mathematical Sciences at RIKEN (iTHEMS).

In the morning of July 29 (Sunday), an onsite workshop on quantum turbulence was held with 12 oral presentations. This workshop was organized by Makoto Tsubota and Wei Guo so as to be complementally to the main symposium and was successful in attracting 50 participants even though conference excursions were offered on the same day.

The symposium spent 5 million JPY ( $\$ 45 \mathrm{k}$ or $€ 39 \mathrm{k}$ ) in total to support registration fees and/or travel expenses for invited speakers and all applicants who were students or from countries where sufficient financial support is difficult to obtain. The total budget of QFS2018 was approximately 20 million JPY (\$18k or €15k). About half of that was financed by the Cryogenic Research Center of the University of Tokyo, KANSAI OSAKA 21st Century Association, Tokyo Convention \& Visitors Bureau (TCVB), the International Union of Pure and Applied Physics (IUPAP), and iTHEMS. The rest of the budget was covered mainly by registration fees from the participants. Five manufacturing companies participated in exhibitions during the first three conference days. They also contributed financially to the organization.

As social programs, a 1-day hiking excursion in the mountains and a half-day city tour excursion of Tokyo were provided on July 29 as well as four half-day city tours for accompanying persons sponsored by TCVB. The conference dinner was held at Hotel New Otani on July 30 and was attended by 143 participants.

Finally, we thank all the committee members who worked to make this symposium successful. More details of QFS2018 are seen at the website: http://www.qfs2018.jpn. org/.

Hiroshi Fukuyama, Conference Chair

Makoto Tsubota, Conference Vice Chair

Takeo Takagi, Chief Guest Editor of Special Issue

Hyoungsoon Choi, Guest Editor of Special Issue

Publisher's Note Springer Nature remains neutral with regard to jurisdictional claims in published maps and institutional affiliations. 